\title{
A UTILIZAÇÃO DE JOGOS PEDAGÓGICOS NO PROCESSO DE ALFABETIZAÇÃO
}

\author{
Leandra de Souza Alves \\ Cledir Rocha Pereira \\ Daniele Raimundo dos Anjos \\ Maria de Fátima Gomes Passos \\ Diógenes José Gusmão Coutinho ${ }^{1}$
}

RESUMO: Este trabalho tem como objetivo analisar a importância dos jogos pedagógicos no processo de alfabetização. Investigando as concepções que os educadores têm a respeito desses recursos para a aquisição da leitura e escrita. A pesquisa foi realizada em duas escolas Municipais, e teve como contribuintes quatro professoras. No qual utilizei uma pesquisa de cunho qualitativa, que comprovei que os jogos pedagógicos proporcionam o desenvolvimento e a formação da aquisição do processo de leitura e escrita. Os resultados apontaram que os jogos contribuem de forma satisfatória para o processo de alfabetização, que essa prática quando inserida na sala de aula estimula o conhecimento, incorporando a comunicação. E o desenvolvimento saudável e construtivo ocorre entre os sujeitos, e com isso viabilizando a convivência em equipe.

Palavras chaves: Jogos pedagógicos. Processo de alfabetização. Leitura e escrita.

ABSTRACT: This work aims to analyze the importance of educational games in the literacy process. Investigating the conceptions that educators have about these resources for the acquisition of reading and writing. The research was carried out in two municipal schools, and had four teachers as contributors. In which I used a qualitative research, which proved that pedagogical games provide the development and formation of the acquisition of the reading and writing process. The results showed that the games contribute satisfactorily to the literacy process, that this practice when inserted in the classroom stimulates knowledge, incorporating communication. And healthy and constructive development takes place among the subjects, thereby making team coexistence possible.

\footnotetext{
${ }^{1}$ Doutor em biologia pela UFPE. Professor da Faculdade Alpha e Unibra. Orientador de dissertações e teses. E-mail: gusmao.diogenes@gmail.com.
} 
Keywords: Pedagogical games. Literacy process. Reading and writing.

\section{INTRODUÇÃO}

$\mathrm{Na}$ atual pesquisa aborda-se a questão dos jogos pedagógicos como ferramenta influenciadora no processo de alfabetização, e certamente no desenvolvimento de habilidades no que se refere à leitura e escrita e compreensão de mundo. Essa pesquisa teve como objetivo geral, analisar a contribuição dos jogos pedagógicos no processo de alfabetização do ensino fundamental I, utilizando os jogos pedagógicos. Dessa forma os objetivos específicos: historicizar a alfabetização no Brasil; verificar como os docentes concebem a importância dos jogos nesse processo; avaliar como são aplicados esses recursos no contexto escolar.

Sabe-se que alguns educadores não têm uma visão positiva dos jogos pedagógicos no que tange o processo de alfabetização. Por esses motivos e entre outros surgiu o interesse de pesquisar a relevância da utilização dos jogos pedagógicos no processo de ensino aprendizagem.

Observa-se que a práxis de tais recursos tende a cumprir uma função significativa no processo de alfabetização dos alunos, no qual todos aprendem de forma saudável, despertando o interesse pelo outro.

Nesse estudo encontra-se na literatura atual teóricos que comungam da utilização dos jogos pedagógicos como fonte de assimilação bem como de ludicidade e criatividade nessa faixa etária da educação e passeando nesse campo descobri-se como a criança gosta de aprender, pois elas devem ser provocadas e convidadas a novos desafios, permanecendo em momentos de concentração, dialogando com o meio em que vive.

Diante mão dos jogos pedagógicos, a criança identifica cada letra e assim sendo, vai construindo e formando palavras, lendo de forma corretamente. (Pode-se refletir 
que apoiado com os jogos as crianças desenvolvem estratégias que estimula os conhecimentos e esses desenvolvem suas potencialidades dentre estas, certamente a leitura e escrita, verifica-se, no entanto o processo de alfabetização embasado com o real, seguramente se tem resultados excelentes, onde se educa e se alfabetiza de maneira construtiva no qual o sujeito vai revelando o lado bom de aprender.

\section{PERCURSO METOdOLÓGICO.}

Entende-se que metodologias são estratégias com o objetivo de orientar uma pesquisa nas mais diversas etapas. Metodologia são procedimentos com o intuito de chegar a possíveis respostas Andrade, (2010). Decidi por esta abordagem, ao despertar

o interesse de conhecer de maneira minuciosa os argumentos dos teóricos e pesquisadores apresentados ao longo da minha formação como: Kishimoto, (2003) Almeida, (2016), Albuquerque, (2005), Santos (1999) entre outros teóricos que conhece ao longo da minha trajetória acadêmica, esses pesquisadores dialogam que os jogos pedagógicos são ferramentas importante na utilização do processo de alfabetização bem como na aquisição da leitura e da escrita.

A abordagem fora realizada com professores que atuam na rede municipal no ensino fundamental I, todas graduadas em pedagogia atuando na área a mais de dez anos, com idade entre 30 e 35 anos e teve como técnicas a observação e análise dos dados que foram interpretados a partir das indagações fora feita as participantes, foram quatro, docentes, nomeadas da seguinte forma, professora um, dois, três e professora quatro, que trabalham na rede municipal de ensino fundamental.

\section{HISTORICIZAR O PROCESSO DE ALFABETIZAÇÃO NO BRASIL}

Ao falar de educação não se pode deixar as nossas leis esquecida, uma delas aqui abordada será a LDB, documento que assegura a educação em todas as suas etapas, uma norma fundamental que aponta a educação como primordial para a formação do cidadão autônomo, possibilitando a sua convivência na sociedade. E 
consequentemente, conquistar a liberdade desde cedo, já que tal liberdade só se tem acesso por meio do estudo, da informação e os frutos desse trabalho serão colhidos quando plantadas no processo de alfabetização, a criança aprende a ler e escrever abrindo portas para outras descobertas.

Sabe-se que da história do processo alfabetização não foi nada fácil, no inicio o ensino era apenas guiados por meio de cartilhas, método sócio linguístico, durante suas pesquisas (MENDONÇA e COREIA apud PAULO FREIRE, 2008, p.I9) relatam que: "Tal método se trata de uma contribuição urgente para estancar o fracasso da alfabetização de crianças das classes populares”. Verifica-se nesse contexto que o ensino era embasado na tendência tradicional, onde o professor depositava o pouco que sabia e o aluno recebia de forma passiva sem questionar.

Porém, diante das lutas e movimentos houve propostas e grandes idéias, buscando mudanças significativas no que se refere à temática abordada, como veremos no decorrer dessa pesquisa, que o processo de alfabetização e uma das fases em que a criança aprende a ler e escrever, a mesma descobre o prazer desses dois objetos de estudos, interagindo com os recursos pedagógicos e a intervenção do educador professor.

O que se pode perceber com a evolução desse processo é, no entanto a quebra de paradigmas, e os estágios de alfabetização sofrem mudanças políticas e sociais,para isso aponta-se o que a Lei de Diretrizes e Bases da Educarão Nacional dialoga.

Em seu art. $\mathrm{I}^{\mathrm{o}}$, a LBD fala que:

A educação abrange os processos formativos que se desenvolvem na vida familiar, na convivência humana, no trabalho, nas instituições de ensino e pesquisa, nos movimentos sociais e organizações da sociedade civil e nas manifestações culturais.

Reflete-se que o pro cesso educativo não se limita somente aqueles que ocorrem nas instituições escolares, certamente a dever de educar é dever de todos que fazem 
parte da sociedade, e esta acontece em todos os lugares cada membro contribuindo com a sua parte.

O processo de alfabetização é visto como uma das etapas crucial para que a o aluno entre em contato com o mundo das letras, e vá descobrindo o prazer de ler e escrever por meio dos recursos pedagógicos que o professor deve presentear ao educando, em suas pesquisas Alexsandro traz sobre a história da alfabetização no Brasil.

A História da Alfabetização, em nosso país, foi centrada na História dos Métodos de Alfabetização. A disputa entre esses métodos, que objetivavam efetivamente garantir aos educandos a inserção no mundo da cultura letrada, produziu uma gama de teorizações e tematizações acerca de estudos e de pesquisas a fim de investigar essa problemática (FERREIRO, 20II, p. 234).

Entende-se que o processo de alfabetização percorreu um longo caminho que tinha como objetivo maior viabilizar o aprendizado do aluno no qual se utilizava vários métodos de alfabetização, sendo que no início as técnicas eram puramente tradicionais, cujo professor era o detector do conhecimento, centro desse processo. Enquanto o aluno era visto apenas como aquele que só recebia esses saberes de maneira bancaria.

Porém com o passar do tempo houve mudanças significativas sobre esse tema, pesquisadores que não se calaram diante das falhas dos antigos métodos, esses que viam os alunos como ser inacabados, certamente não depositava nas crianças confiança de que um dia eles poderiam se tornarem futuros pesquisadores do nosso pais e contudo contribuir para a melhoria da educação.Para Albuquerque (2007,p.12-13).

A alfabetização foi transportada para sala de aula no final do século XIX, mediante a criação de diferentes métodos de alfabetização, métodos sintéticos (silábicos ou fônicos). Métodos analíticos (Global). Que patronearam a aprendizagem da leitura e da escrita.

Compreende-se diante da citação que o processo de alfabetização fora estudado e introduzido com mais força a partir da década 8o, esses viram em sua maioria recheados de críticas referentes aos métodos aplicados em sala de aula. Em meio a tais estudos surgem novas trilhas que passam a ter uma ótica diferenciada e, portanto nasce 
um novo olhar para o aluno. Com Ferreiro temos os níveis de alfabetização, que vai do pré silábica há hipótese alfabética, processos esses que tem por base o olhar flexível do professor alfabetizador. Os estudos de Emilia Ferreiro apontam em direção a métodos inovadores.

As pesquisas de Emilia Ferreiro e colaboradores romperam o imobilismo lamuriento e acusatório e deflagraram um esforço coletivo de busca de novos caminhos. Deslocando a investigação do "como se ensina" para o "como se aprende", Emilia Ferreiro descobriu e descreveu a psicogênese da língua escrita e abriu espaços para um novo tipo de pedagogia. (FERREIRO, 20oI, p.4 e 5).

Verifica-se diante dos estudos de Ferreiro que houve lutas em busca de melhorias no campo da educação, quebrando paradigmas de modelos meramente estéticos e propondo uma nova proposta de ensinar e aprender. Teóricos esses que não se calaram diante do tradicionalismo.

\section{I OS JOGOS PEDAGÓGICOS NO PROCESSO DE ALFABETIZAÇÃO}

Os jogos educativos surgiram por volta do século XVI com intuito de facilitar tarefas de ensinos e orientações, visando à aquisição de conhecimentos, conquistando um espaço permanente no campo da educação, para Leal (2005). O jogo é uma atividade lúdica em que o sujeito se envolve em situações em que tende a desenvolver e aprender regras e normas, respeitando o tempo de cada um em meios as brincadeiras. Portando é nessa cultura que o indivíduo passa a entender o seu direito e dever, exercendo então sua cidadania e agindo como sujeito na sociedade em que vive. Enquanto isso Kishimoto (20II, p.I8), em suas pesquisas dialoga sobre os jogos. "Os jogos podem ser visto como: o resultado de um sistema linguístico que funciona dentro de um contexto social, um sistema de regras e um objeto". Verifica-se então que o jogo diante dos estudos desse teórico tem forte influência social funcionando como canal, para comunicação entre um grupo de indivíduo. Já a professora três lembra que, ”O ensino nessa etapa deve ser enfatizada o uso dos jogos no processo de letramento". Entende- 
se que os dois pontos de vista comungam rumo a utilização dos jogos pedagógicos como ferramenta de aproximação da leitura e escrita.

Levanta-se aqui a relevância da inserção dos jogos pedagógicos durante as aulas de alfabetização, trabalhar com esses recurso é, no entanto desenvolver atividades com o concreto, onde possibilita a visualização dos conteúdos e a identificação do objeto de estudo em foco, e, portanto os alunos aprendem mais e enquanto jogam e brincam se desenvolvem de maneira lúdica, não se pode deixa a ludicidade coberta nesse contexto.

Falando de jogos pedagógicos, esses trazem novas perspectivas e benefícios no que tange o processo de alfabetização. Abordar esses instrumentos no processo de alfabetização requer algumas considerações de como e quando utilizar este recurso didático, e ter a percepção de sua interferência no processo de ensino aprendizagem.

Sabe-se que o uso dos jogos sem nenhuma finalidade especifica pode acarretar lacunas na formação e no processo de aprendizagem, e por isso não favorecer significados positivos para o aluno.

Analisa-se, portanto que o ao exercitar os jogos tende a emergir a inteligência de lhe dar com cada um, despertar de bons sentimentos. Ainda pode-se ir mais longe, na ousadia desses instrumentos tão poderosos e colaborador no despertar de forças no que diz respeito à leitura e escrita, moldando sentimentos dos sujeitos, pois nesse campo surge a espontaneidade artística, criativa estimulando a buscar de novos conhecimentos.

\subsection{JOGOS EDUCATIVOS}

Os jogos são utilizados desde muito tempo, e esses recursos possibilitam a diversão entre as pessoas sejam crianças ou adultos onde todos participam viabilizando a diversão. Com o passar de tempo esses objetos ganham formas, cores e com avanço da tecnologia ficam cada vez mais atrativos se transformando em recursos pedagógicos, e são introduzido na sala de aula com o intuito de alimentar a dinâmica 
do professor fazendo com que a rotina possa ser num ambiente alfabetizador. Possível de se aprender e trocar ideias numa dialogicidade que prime pelo desenvolvimento de capacidades no decorrer das atividades. O trabalho com jogos quando aplicado com um objetivo pode-se ter resultados positivos, enquanto o mesmo recurso se aplicado só por brincar não se tem nenhum resultado, Segundo a professora um.

Trabalhar com jogos pedagógicos é uma forma lúdica de estimular o conhecimento, através deste recurso a criança se envolve nas atividades de forma mais espontânea, aprende a se socializar, principalmente na construção de novos conceitos.

O jogo é considerado uma atividade lúdica que estimula e desenvolve o lado criativo do aluno,incentivando suas habilidades estreitando a relação com o outro. (Leal 2005, p.III). Refletindo com os diálogos acima.

Os jogos pedagógicos facilitam o processo de alfabetização e provavelmente possibilita na assimilação dos conteúdos e com esses procedimentos a aula torna-se mais agradável e o individuo se interessa pelas atividades que são oferecidas. Em seus estudos Leal assevera que: "O jogo é um poderoso recurso que auxilia no processo de alfabetização". Esse recurso é uma ferramenta no qual contribui de maneira rica no processo da aprendizagem.

Entende-se que os jogos utilizados para possibilitar a diversão tanto a criança como o adulto, nesse contexto todos participam da diversão em diversos caminhos com meta de promover novas amizades. Partindo desse ponto o professor deve desenvolver recursos para trabalhar o processo de alfabetização e letramento etapa fundamentais para a aquisição da leitura e escrita.

Quando o jogo é inserido na aula, deixa de fazer parte do brincar só por brincar, passando então o material pedagógico, assim sendo essa ferramenta exerce vários papeis. De acordo com Kishimoto (1998). "Os jogos educacionais facilitam e estimulam a aprendizagem através da interação". 
Reflete-se a luz do teórico citado a cima que com apoio dos jogos o sujeito se desenvolve em todos os aspectos, tais como: desenvolvimento motor, cognitivo, social, intelectual e afetivo.

Aprende-se que a escola é um ambiente em que a crianças ou adolescente deve adquirir conhecimentos e novas habilidade, ela tem objetivos a atingir e por isso qualquer atividade realizada na mesma, busca resultados. Dessa forma, muitas vezes o trabalho lúdico na escola é desvalorizado, seja pelos próprios professores ou até mesmo pelos pais, sabe-se que esse instrumento é valioso nesse processo.

\section{RESULTADOS E DISCUSSÃO}

Esse trabalho teve uma coleta de dados, uma abordagem de campo que utilizei como instrumento de coleta, uma entrevista que continha quatro questões, no qual as perguntas foram abertas, tendo a contribuição de quatro professoras que atuam na rede municipal a mais de ıo anos, e são licenciadas em pedagogia e especialização na área de educação. Por isso entende que as participantes se encontravam preparadas para contribuir com a pesquisa e certamente com tais informações e com isso fui buscando possíveis respostas para o objeto de estudo.

As participantes se mobilizaram na atual pesquisa de maneira profissional e contribuíram para a concretização do trabalho. Pois percebe que as mesmas lançam mão dos jogos pedagógicos para contribuir no processo de alfabetização das crianças viabilizando o aprendizado da leitura e a escrita e, por tais razões elas se identificaram com a temática respondendo com propriedades as perguntas da coleta de dados, presenteando com informações relevantes para o trabalho em foco.

Fora uma participação individual, onde cada uma delas deu sua contribuição, sendo assim foram necessárias quatro visitas para a realização da coletas de dados. Diante mãos dos resultados analisam-se os dados e chega-se o seguinte entendimento. 
Com a introdução dos jogos pedagógicos são ferramentas que comunga com o lúdico, contribuindo de forma favorável no processo de alfabetização. A professora dois dialoga que "os jogos são ferramentas que possibilitam de forma lúdica a aprendizagem dos alunos”. Ainda com a professora dois.

Os jogos pedagógicos podem contribuir para a alfabetização ser mais dinâmica e sem muitas pressões, além de relacionar elementos do cotidiano da criança levando-a a perceber como está cercada por um mundo letrado.

A professora dois desenvolve a prática pedagógica embasados no lúdico, utiliza em sua sala de aula jogos pedagógicos para alfabetizar as crianças, sabe-se que o lúdico é ferramenta nesse acesso e uma maneira de estimular o aluno a tomar gosto pelo estudo.

Durante a análise da coleta de dados, uma das participantes levanta a relevância dos jogos pedagógicos no processo de alfabetização que são objetos que amplia os saberes dos alunos, fazendo com que os mesmos compreendam e assimilem os conteúdos durante as aulas e com isso maximizar os saberes, e certamente o alunado vai formulando novos conceitos a professora um. Dialogando com Santos quando diz que:

Os jogos são experiências vivenciadas que nos dá prazer ao excutala. Por meio da ludicidade a criança se relaciona com o outro e com isso aprende a ganhar e a perder, a respeitar a ordem na fila,a aceitar as frustrações, e a expressar as suas emoções .qualquer atividade que cause uma experiência positiva , divertida e prazerosa pode se chamar de lúdica.(1999,p.49).

Reflete-se nesse mesmo ponto, ficando claro, portanto que as atividades que envolvem as brincadeiras e as crianças aprendem desde cedo a se socializar e conviver em grupo e tendo como consequências positivas à aceitação de normas e regras, contribuindo para um relacionamento saudável, aprendendo a ganhar e a perder lado a lado com o lúdico, e acima de tudo construindo amizades sólidas. Vamos vê o que a quarta entrevistada fala sobre os jogos pedagógicos para o processo de alfabetização do segundo ano das séries iniciais do ensino fundamental I. 
Os jogos quando utilizado como ferramenta de aprofundamento das aprendizagens dos alunos, e escolhendo corretamente esses recursos a serem utilizados, de acordo com a necessidade da turma e com objetivos definidos, compreendendo que as implicações são positivas na prática

Docente.

A luz da fala da entrevistada quando fala que os jogos são imprescindíveis para o processo de aprendizagem, focado aqui o fenômeno da alfabetização, que esse serve como incentivo para trilhar os vários caminhos na descoberta da leitura e escrita, ainda com a entrevista, esses instrumentos devem ser escolhido com metas e serem alcançadas. De acordo com Antunes (2012).

Os jogos em linhas gerais envolvem... O reconhecimento de objetos diferentes. Permitindo associação, comparação, padrões e relacionamento entre eles. A criação de formas de representação (imagens, desenhos, palavras) desse mundo exploram conceitos de quantidade, tempo, causa e efeito, utiliza símbolos abstratos para representar objeto concreto, passando a sugerir o uso de habilidades resolver desafios que envolvam a construção de objetos se relacionando com o instrumento de estudo.. (p.22-23).

Verifica-se que esse autor fala de forma positiva sobre os jogos no que tange o processo de alfabetização buscando nesse contexto um equilíbrio que viabilize o equilíbrio entre os aprendentes e os conteúdos a serem assimilados.

Verifica-se, no entanto que os jogos pedagógicos têm objetivos tais como: trabalhar: as letras iniciais a formação de palavras, associação das imagens, dentre outras funções. Ao longo das discussões percebe-se que os jogos pedagógicos são utilizados com intuito de estimular o acesso de novo conhecimento e o aprendizado se tornar mais prazeroso ficando claro o papel socializador, quando essa ferramenta é utilizada de maneira direta ,tende a implicar no processo de alfabetização das crianças, dessa faixa etária, enriquecido dinâmica da sala de aula e para além dela, aprimorando 
a leitura e escrita. Diante dos jogos a criança vai se apropriando da compreensão tanto da língua escrita como da falada, ampliando a relação social. Dias (2002).

As entrevistadas enfatizaram a importância dos jogos do CEEL. Que contribui para o processo de alfabetização, Segundo Leal et al (2005). Como retrata as imagens a seguir .

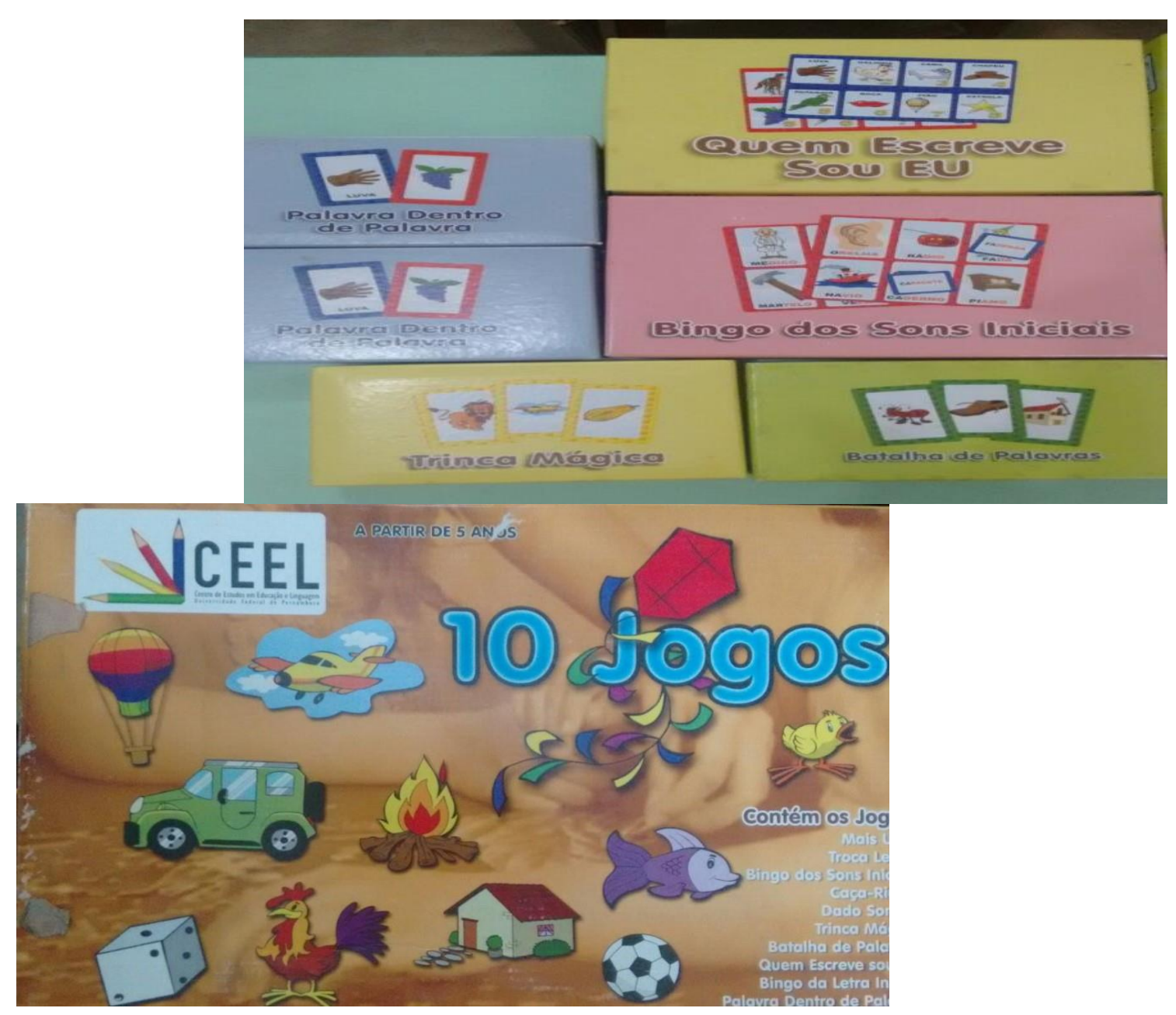




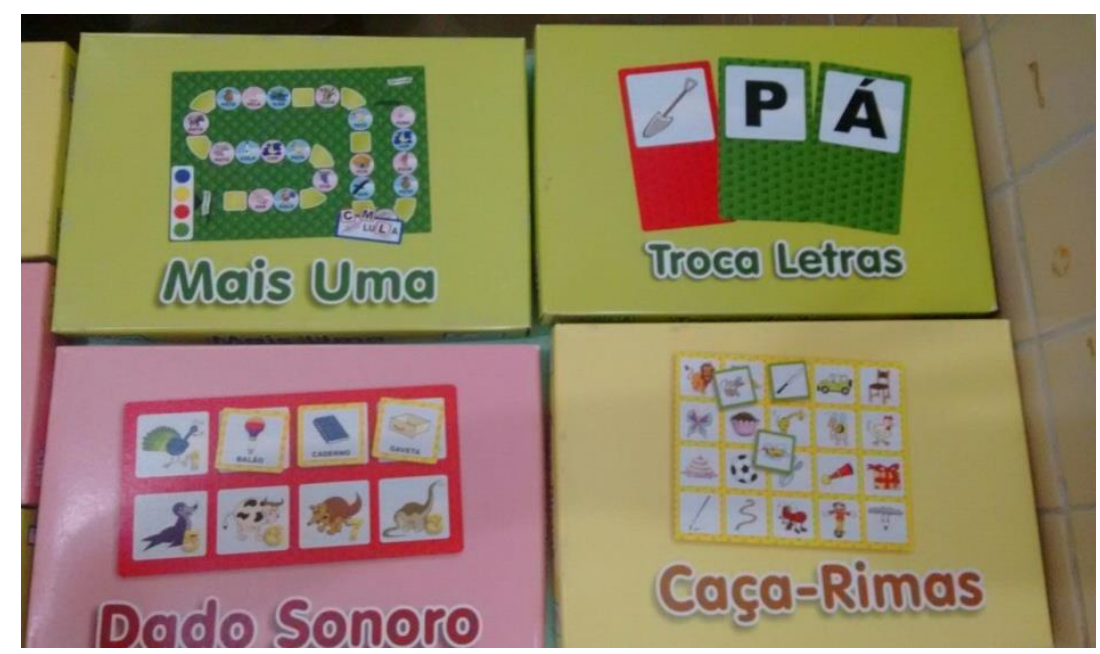

Fonte: Centro de Estudos em Educação e Linguagem

Ressaltam, as professora entrevistadas, "que o professor saiba o que os alunos estão aprendendo, quando participam desses jogos”. Com isso os aprendizes vão aos poucos se apropriando do sistema alfabético e consequentemente, descobrindo as unidades da escrita e da leitura, relacionando os fonemas e grafemas. Andréia et al (2005,p.ri2i).

Apoiada na coleta de dados e nas observações verifica-se claramente o quanto esses materiais são importantes no que se refere o processo de alfabetização, já que se falam da inserção do concreto em sala de aula,uma vez que é diante deles que o aluno vai manipulando cada peça,e assim sendo o aluno aprende, interage e a dinâmica certamente vai se moldando a cada momento uma nova descoberta, um saber diferente ,e a cima de tudo ampliando a criticidade entre todos. A professora três fala que "Com a contribuição dos jogos pedagógicos a criança aprende mais rápido, porque são recursos lúdicos que trazem em seu bojo significados para eles”. Pensa-se, no entanto que o aluno que é alfabetizado com apoio dos jogos pedagógicos se desenvolve por completo e aprendem a ser críticos, a respeitar seus limites bem como o do outro, é, portanto, compartilhar saberes através da cidadania. 
Similarmente os jogos podem ser usados na escola como uma realidade de observação diante de diversos pontos de vista, oportunizando sua comunicação e sustentando a incorporação, professora dois. Kischimoto (200I, p.154), lembra que: "Jogos encantam as crianças, elas são conduzidas a explorar, entender o mundo dos objetos complexos ao seu redor".

Diante de coleta de dados percebe-se de forma ocular que durante as atividades no qual as professoras lançam mãos desses recursos a o ato da aquisição da leitura e escrita se torna momentos que revoa no lúdico e assim sendo a sua aplicação proporcionam para que o letramento ande concomitantemente com o processo de alfabetização, considerando, no entanto os usos das funções da leitura e escrita com resultados satisfatórios.

\section{CONSIDERAÇÕES FINAIS}

Este estudo foi importante, pois se pode perceber o quanto os jogos pedagógicos contribuem no processo de alfabetização do aluno do ensino fundamental I, que essa ferramenta é essencial no desenvolvimento das habilidades de leitura e escrita.

No decorrer deste estudo foi possível fazer uma reflexão da importância dos jogos pedagógicos para o ensino da língua falada, escrita e seu entendimento, e com isso o alunado aprende com prazer, satisfação e realiza descobertas.

Percebe-se que os jogos pedagógicos envolvem diverso conhecimento e esses quando bem aplicados estimula e amplia o processo de alfabetização e o professor pode desenvolver atividades que possam melhorar a leitura e escrita.

Verifica-se, portanto que esses instrumentos viabilizam a formação de valores éticos e morais, formando pessoas mais conscientes de seus direitos e deveres e propícias situações de interação entre os sujeitos, por isso os jogos pedagógicos são relevantes para o sistema de alfabetização. 
Entende-se que a relação dos jogos pedagógicos tem estreita relação com o processo de alfabetização, serve como estratégia pedagógica no caminho do conhecimento da leitura e da escrita.

O educador professor quando usa essas ferramentas viabiliza formação de novos conceitos, ele provavelmente tem como objetivo maior explorar a imaginação do individuo, para que o mesmo sinta-se seguro em realizar suas atividades com autonomia, tanto no coletivo como no individual.

Espera-se que esse trabalho possa contribuir para a produção de recentes concepções ainda não assimilada sobre o tema, desse modo possa também fornecer referências para futuras pesquisas.

A luz dessa atividade e ao longo dessa jornada maximiza-se os conhecimentos no que se refere à temática, descobri que os jogos pedagógicos são ferramentas fundamentais no processo de alfabetização por isso tais recursos são necessários, e assumem imagens e significados que cada grupo social the atribui. (LEAL apud, FROMBERG, 2005, p.122). Ressalta diante dessa grandeza. "Que o jogo representa a realidade e as atitudes humanas".

Os jogos pedagógicos também garantem que o aluno possa construir o Novo, atingindo através de ambientes desafiador o conhecimento, avançando nos esquemas de assimilação e aquisição da língua escrita, num clima recíproco de comunicação numa tríade, professor, aluno e jogo pedagógico.

Valendo salientar que tais recursos fortalecem o processo de alfabetização, que o planejamento da ação pedagógica para alfabetizar seja apoiado nos jogos pedagógicos, por isso os jogos devem ser incorporados no processo de ensino aprendizagem e em especial na faixa etária da alfabetização.

Fora observado durante toda a pesquisa que ao explorar os jogos pedagógicos durante as práticas pedagógicas a dinâmica em sala de aula vai se modificando ficando 
permeada de reflexões sobre a leitura e a escrita, razão essas que alunos que interagem com jogos pedagógicos viabilizam um leque de comunicação entre os colegas e nesse sentido aprendem a ler e escrever realizando o entendimento dos conteúdos que na maioria das vezes estão nas entrelinhas. Uma das educadoras professoras ressalta diante disso que, os jogos pedagógicos são recursos que auxilia no processo de ensino aprendizagem tendo despertando mais o interesse nos estudantes".

É jogando que se deve orientar as crianças para que elas aprendam, e ao mesmo tempo possam se tornar em legítimos educadores seja esses professores ou não, sustentando, com tal projeto, o ampliamento da formação de pessoas que possam contribuir para a educação no futuro.

\section{REFERÊNCIAS}

ALBURQUEQUE, E.B.C. LEAL, T.F.(Org) Alfabetização:apropriação do sistema de escrita. Belo Horizonte. Ed. Autentica. 2005.

AlmedA, Pulo Nunes. Dinâmicos Lúdicos Jogos Pedagógicos. São Paulo Ed.Loyola.1978.

ANDRADE, Maria Margarida. Introdução á Metodologia do Trabalho Científico: elaboração de trabalhos na graduação. ıo ${ }^{\underline{a}}$ edição. São Paulo. Atlas S.A. 2010.

ANTUNES, Celso. Inteligência Múltipla e Seus Jogos: inteligência lógicomatemática. Editora. Vozes, 4ํe edição, vol.6 Petrópolis RJ. 2012.

CONCEIÇÃ̃, Alessandro. Um Breve Histórico da Alfabetização e Letramento no Brasil 〈http://educandoeconversando.blogspot.com.br>/daalfabetizacao-e.html. Acesso em 30 de outubro de 2016 as $17: 30$.

CEEL/UFPE - Centro de Estudos em Educação e Linguagem da Universidade Federal de Pernambuco; MEC - Ministério da Educação. Jogos de Alfabetização. Pernambuco, 2009. http://www.plataformadoletramento.org.br/> Acesso em: 20 de novembro. 2016 as I4h:oo. 
DIAS. C.M. A Importância dos jogos na alfabetização. USP/PEC - trabalho de conclusão de curso, Suzano: 2002.

FERREIRO, Emilia. Reflexões Sobre Alfabetização. São Paulo: ed.atulizada Cortez, 2001.

GALVÃO, Andrea et al.Alfabetização apropriação de sistema de escrita alfabética.Belo Horizonte.Autentica 2005.

KISHIMOTO, Tezuko Morchida. Jogos Infantis, O jogo a criança e a educação, $4^{-a}$ Edição, Petrópolis ed. Vozes, 20II.

Lei Diretriz e Base da Educação Nacional no 9394/96.

MENDONÇA, Onaide Schwartz. OLIMPIA, Correia Mendonça. Alfabetização: método sócio linguistico: consciência silábica e alfabetização em Paulo Freire. ed.São AULO;Cortez.2008.

<meu artigo. Brasil escola. uol.com. br/educação> Utilização Lúdico como ferramenta pedagógica para alfabetização e letramento.Acesso em 25 de abril de 2016.

NASCIMENTO, Josefa de Barros Barbosa. SILVA, Mirian Maria. Contextualizando o Lúdico em Sala de Aula: A Importância do Brincar na Educação Infantil Entre 03-05 anos. Faculdade Joaquim Nabuco. Recife, 2015.

RIBEIRO, Maria Luisa Sprovieri.O Jogo na Organização curricular para deficientes mentais: in:___ KISHIMOTO, Tezuko Morchida.Jogo, Brinquedo Brincadeira e a Educação, I4 ${ }^{\text {a }}$ edição, petrópolis ed. vozes, 2011.p.ı99. 